\title{
Long-Term Outcomes of Multidisciplinary Rehabilitation for Chronic Musculoskeletal Pain
}

Citation for published version (APA):

Volker, G., van Vree, F., Wolterbeek, R., van Gestel, M., Smeets, R., Koeke, A., \& Vlieland, T. V. (2017). Long-Term Outcomes of Multidisciplinary Rehabilitation for Chronic Musculoskeletal Pain. Musculoskeletal Care, 15(1), 59-68. https://doi.org/10.1002/msc.1141

Document status and date:

Published: 01/03/2017

DOI:

10.1002/msc. 1141

Document Version:

Publisher's PDF, also known as Version of record

Document license:

Taverne

Please check the document version of this publication:

- A submitted manuscript is the version of the article upon submission and before peer-review. There can be important differences between the submitted version and the official published version of record.

People interested in the research are advised to contact the author for the final version of the publication, or visit the DOI to the publisher's website.

- The final author version and the galley proof are versions of the publication after peer review.

- The final published version features the final layout of the paper including the volume, issue and page numbers.

Link to publication

\footnotetext{
General rights rights.

- You may freely distribute the URL identifying the publication in the public portal. please follow below link for the End User Agreement:

www.umlib.nl/taverne-license

Take down policy

If you believe that this document breaches copyright please contact us at:

repository@maastrichtuniversity.nl

providing details and we will investigate your claim.
}

Copyright and moral rights for the publications made accessible in the public portal are retained by the authors and/or other copyright owners and it is a condition of accessing publications that users recognise and abide by the legal requirements associated with these

- Users may download and print one copy of any publication from the public portal for the purpose of private study or research.

- You may not further distribute the material or use it for any profit-making activity or commercial gain

If the publication is distributed under the terms of Article $25 \mathrm{fa}$ of the Dutch Copyright Act, indicated by the "Taverne" license above, 
RESEARCH ARTICLE

\title{
Long-Term Outcomes of Multidisciplinary Rehabilitation for Chronic Musculoskeletal Pain
}

\author{
Gerard Volker ${ }^{1}$, Félicie van Vree ${ }^{1,2}$, Ron Wolterbeek ${ }^{3}$, Marc van Gestel ${ }^{1}$, Rob Smeets ${ }^{4,5}$, \\ Albère Köke ${ }^{4,5,6}$ \& Theodora Vliet Vlieland ${ }^{1,2,7 *}$ \\ ${ }^{1}$ Rijnlands Rehabilitation Centre, Leiden, The Netherlands \\ ${ }^{2}$ Sophia Rehabilitation, The Hague, The Netherlands \\ ${ }^{3}$ Department of Medical Statistics, Leiden University Medical Center, Leiden, The Netherlands \\ ${ }^{4}$ Department of Rehabilitation Medicine, Research School of CAPHRI, Maastricht University, The Netherlands \\ ${ }^{5}$ Adelante Centre of Expertise in Rehabilitation and Audiology, Hoensbroek, The Netherlands \\ ${ }^{6}$ Department of Physical Therapy, South University of Applied Sciences, Heerlen, The Netherlands \\ ${ }^{7}$ Dept of Orthopaedics, Rehabilitation and Physical Therapy, Leiden University Medical Center, Leiden, The Netherlands
}

\begin{abstract}
Objectives. Evidence for the effectiveness of multidisciplinary rehabilitation for chronic musculoskeletal pain (CMP) has been reported but its outcomes in the longer term and in mixed groups of chronic pain patients are largely unknown. The aim of the present study was to describe the two-year outcomes of a 15-week multidisciplinary pain rehabilitation programme in patients with mixed CMP in terms of pain, activities, participation and healthcare usage. Methods. Data were recorded routinely at admission, discharge, and at three, 12 and 24 months' follow-up for all consecutive patients with CMP referred to a rehabilitation programme over a 21-month period. The 15-week multidisciplinary rehabilitation programme consisted of cognitive behavioural therapy and exercise, as well as individual and group sessions with additional treatment modalities. Assessments included the Pain Disability Index (PDI), the Pain Catastrophizing Scale (PCS), the Multidimensional Pain Inventory (MPI) and numerical scales for pain and fatigue. Moreover, the RAND-36-Item Health Survey ('RAND-36') and questions on healthcare usage and work status were administered at admission, and at 12 and/or 24 months. Paired $t$-tests, Wilcoxon signed-rank tests, McNemar tests and mixed-model analyses were used to analyse changes over time.

Results. A total of 165 patients were included initially [mean age 44.1 (standard deviation 12.9) years], 143 of whom (87\%) were women, with data from 125 (76\%) and 120 (73\%) patients being available at 12 and 24 months' followup, respectively. All outcomes showed statistically significant improvements between admission and discharge, and at three, 12 and 24 months' follow-up $(p<0.05)$. At 24 months, the median number of different healthcare providers visited in the previous year had decreased significantly compared with that at admission [from a median of 4 (range 1-13) to a median of 2 (range 0-9)], and within the group of patients working at admission (50\%), the proportion of those working 25 hours or more per week had increased significantly from $16 \%$ to $48 \%$.

Conclusions. Improvements in pain and functioning seen directly after a 15-week multidisciplinary treatment programme for patients with CMP were maintained, health care usage decreased and the number of working hours among working patients increased at 24 months' follow-up. Future studies are needed to examine if additional interventions after discharge can enhance further the favourable results. Copyright (c) 2016 John Wiley \& Sons, Ltd.
\end{abstract}

Keywords

Chronic widespread pain; chronic pain; chronic musculoskeletal pain; multidisciplinary treatment; rehabilitation

\section{*Correspondence}

Theodora P. M. Vliet Vlieland, Rijnlands Rehabilitation Centre, P.O. Box 176, 2300 AD Leiden, The Netherlands. Tel: +31 $715195195 ;$ Fax: +31715195190.

Email: T.P.M.Vliet_Vlieland@lumc.nl

Published online 21 April 2016 in Wiley Online Library (wileyonlinelibrary.com) DOI: 10.1002/msc.1141 


\section{Introduction}

Chronic musculoskeletal pain (CMP) is a common condition in the Western world, with a population prevalence of approximately $11 \%$ (Bergman et al., 2001; Croft et al., 1993). There is a body of evidence indicating that the optimal treatment of CMP involves the combination of pharmacological and nonpharmacological interventions. In general, a multicomponent treatment approach that combines exercise and cognitive behavioural therapy (CBT), taking into account the patient's unique needs, appears to be most effective (Hassett and Williams, 2011). Recently, it was suggested that the effects on return to work are probably more pronounced than on pain intensity and physical activity (Swedish Council on Health Technology Assessment, 2010). Moreover, the value of the multi-professional assessment in such approaches is increasingly being recognized (Norrefalk et al., 2010).

The evidence for the effectiveness of multidisciplinary approaches so far has concerned mainly the shortterm outcomes rehabilitation. Of the 35 studies included in a systematic review of multidisciplinary interventions and outcomes in chronic pain, only six reported on outcomes after 12 months (Scascighini et al., 2008). However, these long-term studies included specific subgroups of patients - that is, with chronic back pain or fibromyalgia.

To date, only a limited number of studies have reported on the long-term outcomes of multidisciplinary rehabilitation in mixed groups of patients with CMP in real clinical situations. In a study in patients with CMP in a primary care setting, Westman et al. (2010) showed that, after three years, an experimental group receiving individualized treatment after a multidisciplinary assessment had lower healthcare utilization and a reduced risk of using large amounts of medication than a control group receiving usual care. Another non-controlled study from the same group showed that multidisciplinary treatment improved quality of life and work capacity at up to five years of follow-up (Westman et al., 2006). In addition, Busch et al. (2011) reported a reduction in absences from work due to sickness ten years after various rehabilitation interventions, including multidisciplinary treatment, as compared with standard care. Norrefalk et al. (2010) concluded from a study in patients with CMP, using a historical control group, that a rehabilitation programme had a long- term (six-year) positive effect on the return-to-work rate, level of activity and pain intensity as well as on the consumption of analgesics (Norrefalk et al., 2007). Moreover, this research group reported beneficial effects of both multidisciplinary assessment and multidisciplinary treatment on pain intensity, health perception, physical function and work status after ten years (Bileviciute-Ljungar and Norrefalk, 2014). Another recent observational study showed an improvement in depression and negative emotional cognitions, and control and chronicity beliefs, but not in pain, 18 months after multidisciplinary treatment (De Rooij et al., 2014).

Given the scarcity of studies on the long-term effects of multidisciplinary treatment for CMP in daily practice, the aim of the present study was to describe the outcomes comprehensively - that is, in terms of pain, physical function, work status and health care utilization in the long term ( 24 months). The presentanalysis was a follow-up of two previous reports from our group describing the problems of patients with CMP admitted to a 15-week rehabilitation programme and its effects on pain, activities and participation at discharge (Koele et al., 2014; Meesters et al., 2015).

\section{Methods}

\section{Study design}

The present study concerned the long-term follow-up of a prospective, observational study, from which the short-term data had been published previously (Koele et al., 2014; Meesters et al., 2015). All data were gathered routinely and stored in electronic patient records in connection with a standardized multidisciplinary team care intervention for patients with CMP. In The Netherlands, no permission from a medical ethics committee is required for the evaluation of outcomes of care solely based on data derived from the medical records and executed by the treating physician. At admission, all patients are routinely asked to sign an informed consent form, stating that the data stored in their electronic medical record can be used anonymously by their treating physician for analyses of the outcomes of care. The study, and in particular the handling of the data, was conducted in accordance with the guidelines for good research practice (World Health Organization, 2002). 


\section{Patients}

All consecutive patients with CMP who were eligible for and admitted to the multidisciplinary programme provided at the Rijnlands Rehabilitation Centre, in Leiden, The Netherlands, between 1 March 2011 and 1 December 2012, were eligible for inclusion in the study. All patients lived within a distance of 20 kilometres from the rehabilitation centre.

The inclusion criteria for the programme were: aged $>18$ years; having CMP, with a duration of symptoms $>3$ months; receiving sufficient treatment for an underlying somatic condition, if applicable; having severe limitations in daily activities and participation; and being motivated and able to take part in a multidisciplinary treatment programme for 15 weeks.

Exclusion criteria were: being unable to understand or speak Dutch; participation in a similar rehabilitation programme in the previous three years; involvement in legal procedures related to their chronic pain syndrome; and current, intensive treatment for psychological or work-related problems, irrespective of whether it was connected to their chronic musculoskeletal pain.

A team comprising a physician, psychologist and physical therapist screened each patient for eligibility for the programme, and the final decision was based on consensus.

\section{Intervention}

All eligible patients took part in the same outpatient multidisciplinary programme at the rehabilitation centre. A multidisciplinary team comprising a rehabilitation physician, an occupational therapist, a social worker, a psychologist and a physical therapist provided the programme. The overall goal was to optimize patients' functioning with respect to activities and participation by supporting them in managing their pain. The programme employed a personalized approach, within a largely standardized programme structure. The programme involved the following treatment modalities: CBT, education, individual and group exercise, relaxation and hydrotherapy. In the Netherlands, rehabilitation centres are currently reimbursed based on fixed prices for a combination of diagnosis and treatment. In 2015, the tariff for multidisciplinary rehabilitation for chronic musculoskeletal conditions varied between 2,200 and 6,700 euro, depending on, among other factors, the number of treatment hours.

\section{Assessments}

Data were gathered and entered into a central database by the treating healthcare providers as part of routine clinical care and follow-up at the start of the programme and at discharge, and then at three, 12 and 24 months' follow-up. Assessments included both paper- and computer-based questionnaires to be completed by the patients, as well as interviews performed by health professionals. The follow-up at three, 12 and 24 months consisted only of the administration of paper surveys, sent by regular mail. Questions on working status, use of the subscales of the RAND-36 (Hays et al., 1993; van der Zee and Sanderman, 1993) and an inventory of healthcare usage in the previous 12 months were carried out only at 0 and 24 months.

\section{Admission assessments}

\section{Sociodemographics and disease characteristics}

The sociodemographic data registered at admission included: age (years), gender (male/female), living status (alone/together), educational level (low $=$ up to and including lower technical and vocational training; medium = up to and including secondary technical and vocational therapy; high = up to and including higher technical and vocational training and university).

\section{Disease characteristics}

The characteristics of CMP included: location of symptoms (12 regions), duration of chronic pain symptoms (years) and past treatment.

\section{Outcome assessments}

\section{Pain}

Pain was measured by using the following instruments:

- Two 0-10 numerical rating scales (NRS pain) (Hawker et al., 2011), one pertaining to average pain over the previous seven days and one pertaining to the worst moments in the previous seven days $(0=$ is no pain at all; $10=$ worst pain imaginable $) . A$ reduction of 2 points or $30 \%$ was assumed to be clinically important (Dworkin et al., 2008).

- The Pain Disability Index (PDI) (Pollard, 1984; Soer et al., 2012) records the level of disability that patients experience for each of the seven categories of life activities $(0=$ no disability at all; $10=$ all 
activities are disrupted/prevented by pain), with the total score ranging from 0 to 70 . In patients with chronic back pain, the minimal clinically important change has been reported to be 8.5-9.5 points (Soer et al., 2012).

- The Pain Catastrophizing Scale (PCS) (Sullivan et al., 1995) measures catastrophizing related to pain. It contains 13 items that can be divided into three subscales (rumination, magnification and helplessness). The items are rated on a five-point scale $(0=$ not at all; $4=$ always $)$. The PCS total score is computed by summing responses to all 13 items. PCS total scores range from 0 to 52 .

- The Multidimensional Pain Inventory (MPI) (Kerns et al., 1985) assesses the impact of pain, responses by significant others and its effect on general activity level. It has a total of 12 subscales, in the present study, only the pain severity subscale was used. This subscale assesses pain severity and suffering on a seven-point Likert scale (0-6), with higher values representing higher levels of pain severity.

\section{Fatigue}

Fatigue over the previous seven days was measured using a self-administered $0-10$ numerical rating scale (NRS fatigue $) \quad(0=$ no fatigue; $10=$ completely exhausted).

\section{Overall quality of life}

Overall quality of life was measured using four subscales of the RAND-36: physical functioning, rolephysical functioning, mental functioning, and vitality. The score for each subscale ranges from 0 to 100 (Hays et al., 1993; van der Zee and Sanderman, 1993).

\section{Healthcare and pain medication usage in the previous 12 months}

The usage of care provided by various healthcare providers (except the general practitioner; yes/no) and the use of pain medication (categorized into: seldom or never to 1-3 times per month; 1-6 times per week; once a day or more) in the past 12 months were recorded. The proportions of patients reporting one or more visits to the physiotherapist ( $88 \%$ versus $64 \%$ ), occupational therapist (9\% versus 3\%), orthopaedic surgeon $(23 \%$ versus $15 \%)$, rheumatologist ( $48 \%$ versus $12 \%$ ), neurologist ( $44 \%$ versus $15 \%$ ), rehabilitation anaesthetist (34\% versus $17 \%)$, psychologist (26\% versus $14 \%)$ or social worker (11\% versus $4 \%$ ) in the previous year were significantly lower at 24 months than at admission.

\section{Work status}

Questions on work status included current work status (paid job, study/school, other) and, if having a paid job, the average number of hours of working per week (categorized into: 0; 1-24; and $\geq 25$ hours per week).

\section{Statistical analysis}

Descriptive statistics were used for the admission characteristics of the patients. Comparisons between patients with up to and including 24 months followup and patients who dropped out before 24 months were carried out by means of unpaired $t$-tests or the Mann-Whitney $U$ test for continuous variables, or Fisher's exact test for categorical variables. Statistical comparisons of outcome measures between admission and 24-months' follow-up included the Wilcoxon signed-rank test or McNemar test, where appropriate. Mean estimates for the various time points were calculated by using a linear mixed-model procedure with a heterogeneous Toeplitz covariance matrix for the repeated measures and time as a factor. This approach takes the correlated nature of repeated measures from the same patient into account, while accommodating for missing observations and allowing post-hoc tests for within-patient factors. Although run as a mixed-model procedure, the model used was in fact a marginal linear model as no random effects were included. This analysis included the computation of Hedges' $g$ effect sizes by using standard errors from the mixed-model output to derive pooled and weighted standard deviations (Hedges, 2007) In general, an effect size (ES) of $>0.80$ is considered large, $>0.50$ moderate and $<0.20$ small (Cohen, 1988). The normality assumption for the various outcome variables was checked by visual inspection of the residuals. All analyses were done using SPSS Statistics for Windows, Version 22.0 (IBM Corp, Armonk, NY, USA).

\section{Results}

The flow of patients is depicted in Figure 1. Of the 263 patients who were referred to the rehabilitation programme during the study period, 165 were considered to be eligible for the programme and provided 


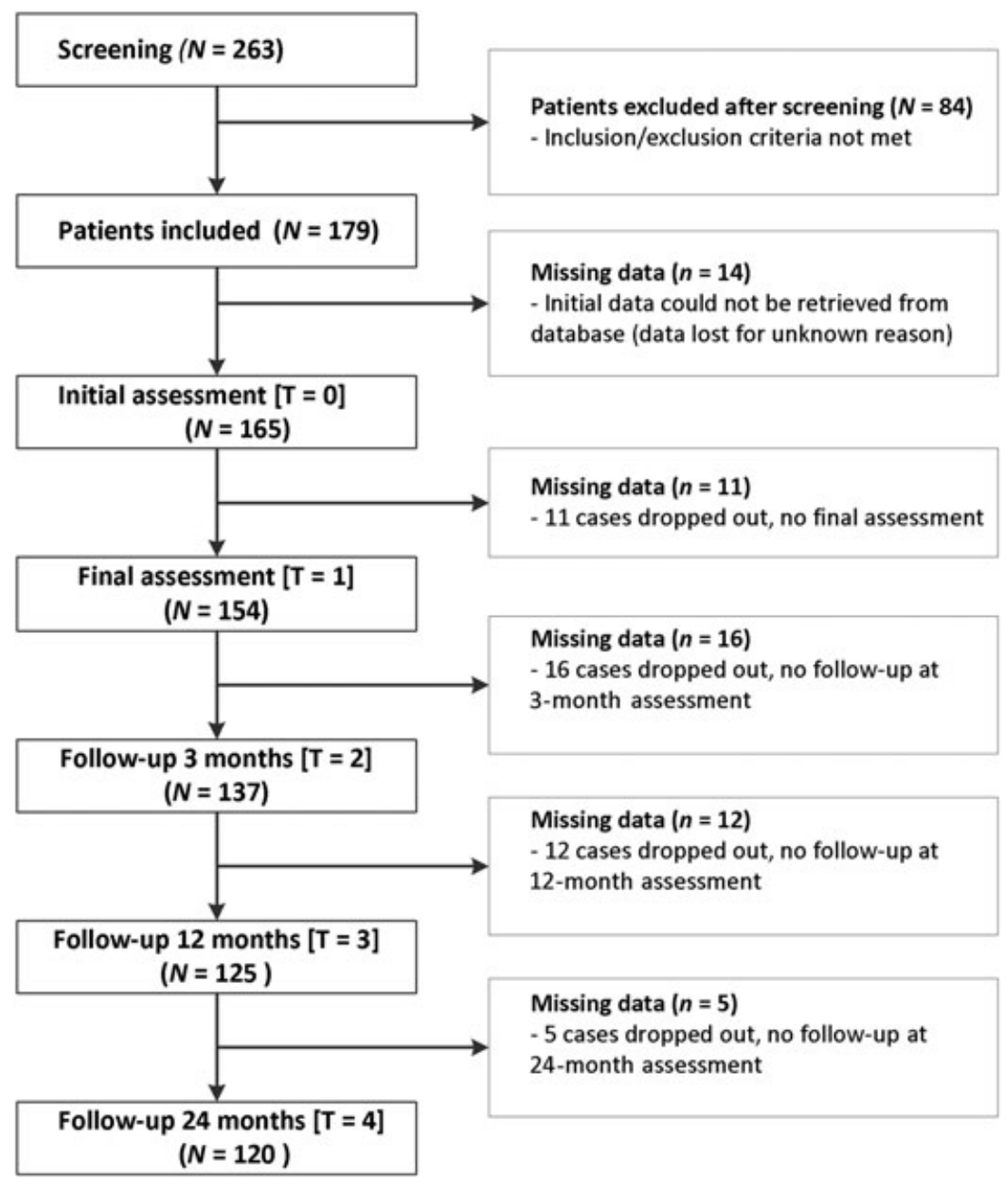

Figure 1. Flow of patients with chronic musculoskeletal pain referred to a 15-week multidisciplinary team care programme

admission data. Data from $137(83 \%), 125(76 \%)$ and $120(73 \%)$ patients were available at three, 12 and 24 months' follow-up, respectively. The reasons for exclusion and drop-out were not recorded systematically for every patient.

\section{Patient characteristics}

Table 1 shows the characteristics of the patients. Their mean age was 44.1 years, and 143 (87\%) were women. The median number of pain sites was four, with the locations of the symptoms most frequently mentioned being the back $(n=115,71 \%)$, shoulder(s) $(n=98$, $60 \%)$ and neck $(n=84,52 \%)$.

Two-thirds of the patients had a duration of symptoms of five years or more. Half of the patients were referred by the general practitioner, and the other half by various medical specialists. Before referral, most patients had already had contacts with multiple healthcare providers. Three-quarters of the patients used pain medication, and three-quarters had formal or informal help with daily activities. The admission characteristics of the 120 patients with complete follow-up were not statistically significantly different from those who dropped out prematurely $(n=45)$ (results not shown).

\section{Pain, fatigue and quality of life}

Table 2 and Figures 2 and 3 show that, in general, statistically significant improvements $(p<0.05)$ in comparison with admission data were seen for all endpoint measures, at all time points from discharge up to and including the 24-months follow-up. The proportions of patients achieving minimally clinically important differences at discharge were $44 \%(n=46)$, 
Table 1. Characteristics of 165 patients with chronic musculoskeletal pain taking part in a 15 -week rehabilitation programme

\begin{tabular}{|c|c|}
\hline \multicolumn{2}{|l|}{ Sociodemographic characteristics } \\
\hline $\begin{array}{l}\text { Age, years; mean } \\
(\text { standard deviation) } \\
(n=165)\end{array}$ & $44.1(12.9)$ \\
\hline $\begin{array}{l}\text { Gender, female } \\
(n=165)\end{array}$ & $143(87 \%)$ \\
\hline \multicolumn{2}{|l|}{$\begin{array}{l}\text { Educational level } \\
(n=158)\end{array}$} \\
\hline Low & $52(33 \%)$ \\
\hline Medium & $76(48 \%)$ \\
\hline High & $30(19 \%)$ \\
\hline $\begin{array}{l}\text { Living status, living } \\
\text { alone }(\mathrm{n}=159)\end{array}$ & $20(12 \%)$ \\
\hline \multicolumn{2}{|l|}{$\begin{array}{l}\text { alone }(\mathrm{n}=159) \\
\text { Work status }(n=159)\end{array}$} \\
\hline Paid job & $77(48 \%)$ \\
\hline School, study & $6(4 \%)$ \\
\hline Volunteer or household & $76(48 \%)$ \\
\hline \multirow{2}{*}{\multicolumn{2}{|c|}{$\begin{array}{l}\text { work, disability pension, retired, } \\
\text { looking for a job or other }\end{array}$}} \\
\hline & \\
\hline \multicolumn{2}{|l|}{ Characteristics of pain symptoms, } \\
\hline \multicolumn{2}{|l|}{ healthcare usage and treatment } \\
\hline \multicolumn{2}{|l|}{ expectancies } \\
\hline \multicolumn{2}{|l|}{ Location of symptoms $(n=163)$} \\
\hline Head & $30(18 \%)$ \\
\hline Face or throat & $13(8 \%)$ \\
\hline Neck & $84(52 \%)$ \\
\hline Shoulder(s) & $98(60 \%)$ \\
\hline $\operatorname{Arm}(s)$ & $58(36 \%)$ \\
\hline Hand(s) and/or finger(s) & $65(40 \%)$ \\
\hline Breast and/or abdomen & $13(8 \%)$ \\
\hline Back & $115(71 \%)$ \\
\hline $\operatorname{Hip}(s)$ & $63(39 \%)$ \\
\hline Upper leg(s) and/or knee(s) & $79(48 \%)$ \\
\hline Ankle(s) and/or foot/feet & $58(36 \%)$ \\
\hline Other & $34(21 \%)$ \\
\hline $\begin{array}{l}\text { Average number of pain sites; } \\
\text { median (range) }(n=163)\end{array}$ & $4(1-11)$ \\
\hline \multicolumn{2}{|l|}{ Duration of symptoms $(n=162)$} \\
\hline $0.5-1$ year & $7(4 \%)$ \\
\hline $1-2$ years & $14(9 \%)$ \\
\hline $2-5$ years & $36(22 \%)$ \\
\hline More than 5 years & $105(65 \%)$ \\
\hline \multicolumn{2}{|l|}{$\begin{array}{l}\text { Referring professional } \\
(n=162)\end{array}$} \\
\hline General practitioner & $86(53 \%)$ \\
\hline Rheumatologist & $25(15 \%)$ \\
\hline Anaesthetist or pain specialist & $21(13 \%)$ \\
\hline Rehabilitation specialist & $16(10 \%)$ \\
\hline Other & $14(9 \%)$ \\
\hline
\end{tabular}

All values are numbers (\%), unless otherwise stated.

${ }^{*}$ Educational level: low $=$ up to and including lower technical and vocational training; medium $=$ up to and including secondary technical and vocational training; high = up to and including higher technical and vocational training and university
$37 \%(n=38), 44 \%(n=44)$ and 55\% $(n=47)$ for NRS pain in the previous week, NRS pain on the worst days in the previous week, NRS fatigue in previous week and PDI, respectively. These proportions showed no significant decrease at 24 months [42\% $\quad(n=44), \quad 35 \%$ $(n=36), 34 \%(n=34)$ and $52 \%(n=45)$, respectively]. (related-samples McNemar's test).

At 24 months, moderate ESs $(>0.50)$ were seen for NRS pain, NRS fatigue, the PDI and the PCS, whereas the ES of the MPI was small.

With regard to quality of life, the ESs of the RAND36 at 24 months were all moderate, except for the RAND-36 physical functioning subscale (ES 0.32, small).

Although, for each pain site, there was no difference in the proportion of patients reporting pain (results not shown), the median total number of pain sites per patient decreased from four (range 1-11) to three (range $0--11$ ) between admission and 24 months.

\section{Healthcare and pain medication usage}

Table 3 shows that the proportions of patients reporting the usage of pain medication once a week or more did not differ between admission and discharge. However, at 24 months' follow-up, there was a significant decrease in the median number of different healthcare providers that patients had used (median 4 , range $1-13$ to median 2 , range $0-9$; $p<0.001$ ) as compared with admission. The proportions of patients reporting one or more visits to the physiotherapist (88\% versus 64\%), occupational therapist (9\% versus $3 \%$ ), orthopaedic surgeon (23\% versus $15 \%$ ), rheumatologist (48\% versus $12 \%$ ), neurologist $(44 \%$ versus $15 \%)$, rehabilitation anaesthetist (34\% versus $17 \%$ ), psychologist (26\% versus $14 \%$ ) or social worker ( $11 \%$ versus $4 \%$ ) in the previous year were significantly lower at 24 months than at admission.

\section{Work status}

The proportions of patients reporting that they had a paid job at admission and at 24 months' follow-up were similar ( $48 \%$ and 50\%, respectively). However, the numbers of patients reporting to work 0 hours or 124 hours decreased significantly, from $22 \%$ to $0 \%$ and from $62 \%$ to $53 \%$, respectively, whereas the numbers of patients working $\geq 25$ hours per week increased (from $16 \%$ to $48 \%$ ). 
Table 2. Admission and follow-up values ${ }^{\dagger}$ of measures of pain, fatigue and quality of life in patients with chronic musculoskeletal pain taking part in a multidisciplinary rehabilitation programme $e^{\ddagger}$

\begin{tabular}{|c|c|c|c|c|c|c|}
\hline & $\begin{array}{l}\text { Admission } \\
(n=165) \\
\text { Mean (SD) }\end{array}$ & $\begin{array}{l}\text { Discharge } \\
(n=154) \\
\text { Mean (SD) }\end{array}$ & $\begin{array}{c}3 \text { months } \\
(n=137) \\
\text { Mean (SD) }\end{array}$ & $\begin{array}{l}12 \text { months } \\
(n=125) \\
\text { Mean (SD) }\end{array}$ & $\begin{array}{c}24 \text { months } \\
(n=120) \\
\text { Mean (SD) }\end{array}$ & $\begin{array}{l}\text { Effect size } \\
\S \text { Admission to } \\
24 \text { months }\end{array}$ \\
\hline \multicolumn{7}{|l|}{ Pain } \\
\hline $\begin{array}{l}\text { Pain in the previous } \\
\text { week (NRS 0-10) }\end{array}$ & $6.6(1.6)$ & $5.2(2.0)$ & $5.5(1.9)$ & $6.0(2.0)$ & $5.3(2.2)$ & 0.71 \\
\hline $\begin{array}{l}\text { Pain on the worst } \\
\text { days in the previous } \\
\text { week (NRS } 0-10 \text { ) }\end{array}$ & $8.2(1.3)$ & $7.1(2.0)$ & $7.4(1.9)$ & $7.4(2.0)$ & $6.8(2.6)$ & 0.72 \\
\hline $\begin{array}{l}\text { Pain Disability Index } \\
(0-70)\end{array}$ & $37.8(10.3)$ & $28.4(11.5)$ & $31.3(12.1)$ & $31.9(12.4)$ & $29.7(13.2)$ & 0.70 \\
\hline $\begin{array}{l}\text { Pain Catastrophizing } \\
\text { Scale }(0-52)\end{array}$ & $17.5(9.6)$ & $11.1(8.2)$ & $10.5(7.8)$ & $10.7(6.3)$ & $12.6(9.1)$ & 0.51 \\
\hline $\begin{array}{l}\text { Multidimensional Pain } \\
\text { Inventory }(0-54)\end{array}$ & $3.9(1.1)$ & $3.7(1.1)$ & $3.6(1.1)$ & $3.8(1.1)$ & $3.4(1.4)$ & 0.44 \\
\hline \multicolumn{7}{|l|}{ Fatigue } \\
\hline $\begin{array}{l}\text { Fatigue in the previous } \\
\text { week (NRS 0-10) }\end{array}$ & $7.3(1.6)$ & $5.8(2.1)$ & $6.4(1.8)$ & $6.8(2.0)$ & $6.3(2.2)$ & 0.58 \\
\hline \multicolumn{7}{|l|}{ Quality of life } \\
\hline $\begin{array}{l}\text { RAND-36 physical } \\
\text { functioning }(0-100)\end{array}$ & 46.4 (19.7) & $56.4(21.4)$ & & & $53.4(25.0)$ & 0.32 \\
\hline $\begin{array}{l}\text { RAND-36 role-physical } \\
(0-100)\end{array}$ & $14.6(26.9)$ & $39.1(36.2)$ & & & $31.2(37.6)$ & 0.52 \\
\hline $\begin{array}{l}\text { RAND-36 vitality } \\
(0-100)\end{array}$ & $36.4(15.0)$ & $51.4(16.7)$ & & & $46.0(18.3)$ & 0.58 \\
\hline $\begin{array}{l}\text { RAND-36 mental } \\
\text { functioning }(0-100)\end{array}$ & $61.3(18.3)$ & $71.0(15.6)$ & & & $70.1(17.0)$ & 0.49 \\
\hline
\end{tabular}

${ }^{\dagger}$ Mean estimates for the various time points were calculated using a linear mixed-model procedure.

${ }^{\ddagger}$ All differences between admission and 24 months' follow-up time points are statistically significant.

${ }^{\S}$ Hedges' $g$ effect size. For the effect size, 0.2 is considered a small effect, 0.5 a moderate effect and 0.8 a large effect.

NRS, numerical rating scale; RAND-36, RAND-36-Item Health Survey; SD, standard deviation.

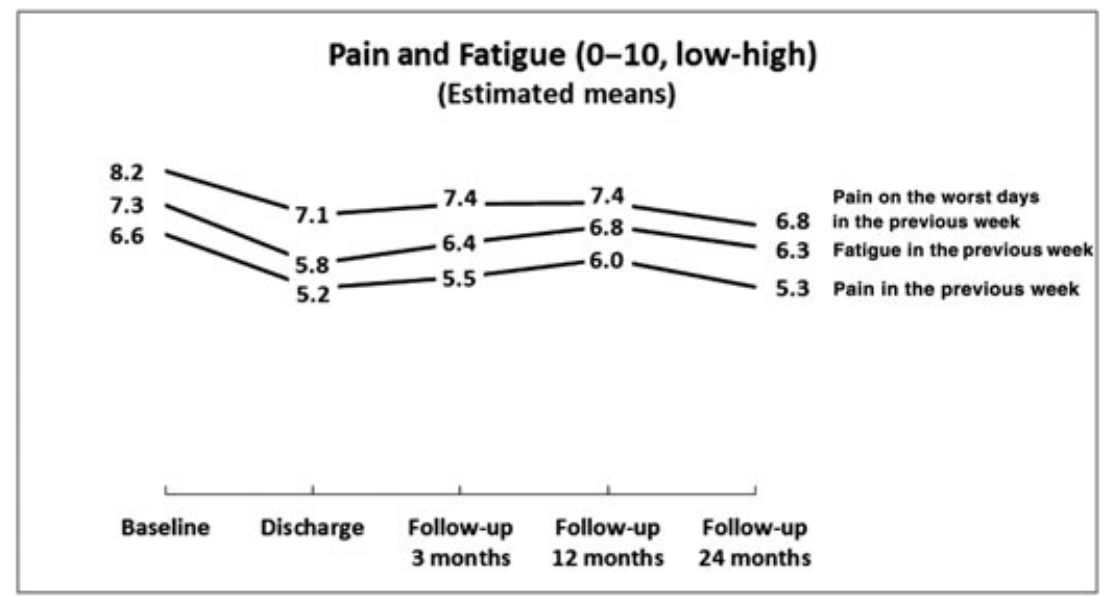

Figure 2. Estimated mean admission and follow-up numerical rating scale scores for pain and fatigue in patients with chronic musculoskeletal pain 


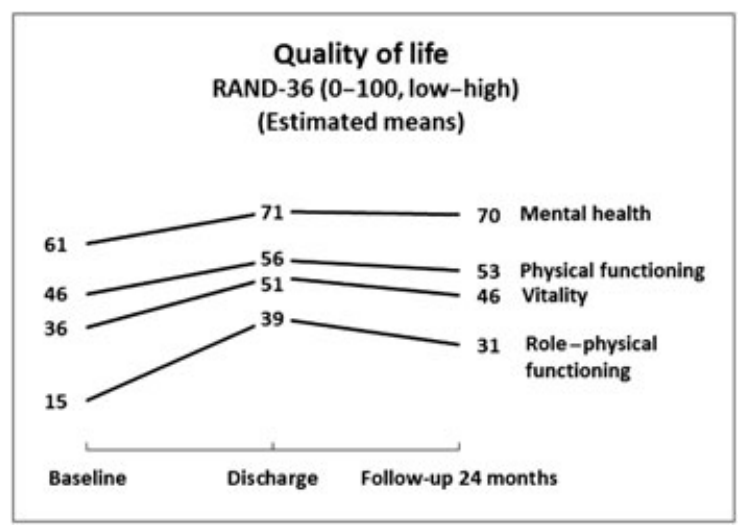

Figure 3. Estimated mean admission and follow-up scores of RAND-36 subscales in patients with chronic musculoskeletal pain

\section{Discussion}

The present observational study reflecting daily pain rehabilitation practice showed that, in the Netherlands, in a mixed population of patients with CMP participating in a 15-week multidisciplinary team care programme, improvements in pain, fatigue and quality of life attained at discharge were also maintained up to 24 months' follow-up. Apart from an improvement in patients' health status, a significant decrease in healthcare usage and an increase in the number of working hours among patients working at admission were observed.

These results are largely in line with the limited number of long-term ( $>12$ months) follow-up studies of multidisciplinary approaches in this patient group (Westman et al., 2006; Westman et al., 2010; Busch et al., 2011; Norrefalk et al., 2007; Bileviciute-Ljungar et al., 2014; de Rooij et al., 2014), although there were differences in the interventions and the outcome measures employed.
In contrast to the results of the present study, in some of the other studies a multidisciplinary programme on pain was found to have no effect. The positive effect on pain in the present study was observed with the intervention targeted on the regain of activities and participation rather than on pain reduction. Regarding the beneficial effect on work status, a favourable outcome was seen in those patients who had a paid job at admission. This is striking, as some of the interventions in the long-term studies on the outcomes of multidisciplinary treatment of CMP were far more focused on the return to work (Norrefalk et al., 2007) than was the treatment programme in the present study.

Only a few patients who did not have paid employment at admission had acquired a job at follow-up. It remains to be established, however, to what extent these patients were aspiring to paid employment or not, and/or to what extent extra efforts aimed at the re-attainment of paid work in those not working would have improved the outcomes in this subgroup.

The favourable effect on work status, as well as the significant reduction in healthcare usage, seen in the present study suggests that the intervention may be cost-effective from the societal as well as the healthcare perspective. To establish the cost-effectiveness, however, an in-depth economic study is needed.

The duration of the programme employed in the present study was somewhat longer than the average duration of multidisciplinary pain rehabilitation programmes in the Netherlands, which is 12 (range 4-20) weeks (Goossens et al., 2002). So far, the optimal duration according to outcome remains unclear. Waterschoot et al. (2014) identified 18 studies with a wide variety of dose variables in a systematic review on dose-response relationships in pain

Table 3. Usage of pain medication and healthcare services, and work status of patients with chronic musculoskeletal pain taking part in a multidisciplinary rehabilitation programme at admission and at 24 months' follow-up

\begin{tabular}{|c|c|c|c|}
\hline & Admission $N=165$ & 24 months' follow-up $N=120$ & \\
\hline \multicolumn{4}{|l|}{ Usage of pain medication and healthcare services } \\
\hline $\begin{array}{l}\text { Use of painkillers on at least a weekly basis; } \\
\text { number (\%) }\end{array}$ & $119(75 \%)(n=158)$ & $83(69 \%)(n=120)$ & $p=0.263$ \\
\hline $\begin{array}{l}\text { Number of healthcare providers seen for pain over the } \\
\text { previous } 12 \text { months; median (range) }\end{array}$ & $4(1-13)$ & $2(0-9)$ & $p<0.001$ \\
\hline \multicolumn{4}{|l|}{ Work status } \\
\hline Having a paid job; number (\%) & $77(48 \%)(n=159)$ & $58(50 \%)(n=117)$ & $p=0.832$ \\
\hline Number of working hours per week; number (\%) & $16(22 \%)$ & $0(0 \%)$ & $p<0.05$ \\
\hline 0 & $45(62 \%)$ & $29(53 \%)$ & \\
\hline $1-24$ & $12(16 \%)$ & $26(48 \%)$ & \\
\hline$>24$ & $(n=73)$ & $(n=55)$ & \\
\hline
\end{tabular}


rehabilitation. The duration of pain rehabilitation in the included studies ranged from 3 to 15 weeks in this review, with an average of seven weeks. No conclusions could be drawn for the optimal dose-response relationship because dose variables were never studied specifically, warranting the need for future studies focusing on this aspect.

Regarding the composition of the intervention, recent literature suggests that the multidisciplinary assessment may be in itself an active element of a multidisciplinary approach, apart from the ensuing treatments (Norrefalk et al., 2010). As in the present study, the multidisciplinary assessment and a number of treatments were fixed components of the intervention, so no conclusions on the effect of the assessment alone could be drawn (Norrefalk et al., 2010). In the present study, 84 of 263 patients were excluded after the initial assessment but no information on their outcome was gathered.

The present study had several limitations. First, the design was observational, and no control group was used for comparison. Therefore, it cannot be ruled out that the improvements seen can be explained by 'regression to the mean'. Data were gathered by healthcare providers, potentially leading to more favourable results than those obtained by independent assessors. In addition, there were various selection criteria for admission to the programme, so that patients with the worst prognosis were probably excluded. Unfortunately, in the present study, the reasons for exclusion were not recorded systematically. Moreover, the data were gathered in daily practice, with a relatively high proportion of missing data. Reasons for dropouts were not recorded systematically. However, by using a mixed-model statistical approach, with its maximum likelihood estimates, the optimal use of all available data was ensured. Another weakness of the present study is the fact that the underlying diagnoses of patients (e.g. osteoarthritis or chronic low back pain) were not recorded systematically at admission. Therefore, it remains unclear if specific diagnosis groups may benefit more or less from the programme. In spite of these limitations, the results of the present study are promising, showing that multidisciplinary treatment is effective, even though effect sizes were moderate, especially taking into account that most of these patients were seeing many health professionals and were partly or totally out of work. Furthermore, even two years later, the benefits were still present, with a sustained effect on healthcare usage and employment. These favourable outcomes warrant additional research, preferably including an economic analysis. More attention should now be given to the effect of the multidisciplinary assessment alone, and also to the regaining of paid work among those who are not in work.

\section{Acknowledgements}

We are indebted to Lineke Holtsappel for practical support in the follow-up study.

\section{REFERENCES}

Bergman S, Herrström P, Högström K, Petersson IF, Svensson B, Jacobsson LTH (2001). Chronic musculoskeletal pain, prevalence rates, and sociodemographic associations in a Swedish population study. Journal of Rheumatology 28: 1369-77.

Bileviciute-Ljungar I, Norrefalk J-R (2014). Beneficial long-term effects of multiprofessional assessment vs. rehabilitation program in patients with musculoskeletal pain. Pain Practice 3: 228-36.

Busch H, Bodin L, Bergstrom G, Jensen IB (2011). Patterns of sickness absence a decade after pain-related multidisciplinary rehabilitation. Pain 152: 1727-33.

Cohen J (1988). Statistical Power Analysis for the Behavioral Sciences (2nd edn). Hillsdale, NJ: Erlbaum.

Croft P, Rigby AS, Boswell R, Schollum J, Silman A (1993). The prevalence of chronic widespread pain in the general population. Journal of Rheumatology 20: 710-3.

De Rooij A, de Boer MR, van der Leeden M, Roorda LD, Steultjens MPM, Dekker J (2014). Cognitive mechanisms of change in multidisciplinary treatment of patients with chronic widespread pain: A prospective cohort study. Journal of Rehabilitation Medicine 46: 173-80.

Dworkin RH, Turk DC, Wyrwich KW, Beaton D, Cleeland CS, Farrar JT, Haythornthwaite JA, Jensen MP, Kerns $\mathrm{RD}$, Ader DN, Brandenburg N, Burke LB, Cella D, Chandler J, Cowan P, Dimitrova R, Dionne R, Hertz S, Jadad AR, Katz NP, Kehlet H, Kramer LD, Manning DC, McCormick C, McDermott MP, McQuay HJ, Patel S, Porter L, Quessy S, Rappaport BA, Rauschkolb C, Revicki DA, Rothman M, Schmader KE, Stacey BR, Stauffer JW, von Stein T, White RE, Witter J, Zavisic S (2008). Interpreting the clinical importance of treatment outcomes in chronic pain clinical trials: IMMPACT recommendations. Journal of Pain 9: 105-21.

Goossens M, Köke AJA, Tilli D (2002). Multidisciplinaire Pijnrevalidatie in Nederland [Multidisciplinary pain rehabilitation in The Netherlands]. Nederlands Tijdschrift voor Pijnbestrijding 22: 7-13.

Hassett AL, Williams DA (2011). Non-pharmacological treatment of chronic widespread musculoskeletal pain. Best Practice and Research in Clinical Rheumatology 25: 299-309. 
Hawker GA, Mian S, Kendzerska FM (2011). Measures of adult pain. Arthritis Care and Research 63: 240-52.

Hays RD, Sherbourne CD, Mazel RM (1993). The RAND 36-Item Health Survey 1.0. Health Economics 2: 217-27.

Hedges LV (2007). Effect sizes in cluster-randomized designs. Journal of Educational and Behavioral Statistics 32: 341-70.

Kerns RD, Turk DC, Rudy TE (1985). The West HavenYale Multidimensional Pain Inventory (WHYMPI). Pain 23: 345-56.

Koele R, Volker G, van Vree F, van Gestel CM, Koke A, Vliet Vlieland T (2014). Multidisciplinary rehabilitation for chronic widespread musculoskeletal pain: Results from daily practice. Musculoskeletal Care 12: 210-20.

Meesters JJ, Volker G, Koele R, van Gestel CM, Smeets RJ, Vliet Vlieland TPM (2015). Problems in functioning in patients with chronic musculoskeletal pain admitted for multidisciplinary rehabilitation. Pain Practice [epub ahead].

Norrefalk JR, Linder J, Ekholm J, Borg K (2007). A 6-year follow-up study of 122 patients attending a multiprofessional rehabilitation programme for persistent musculoskeletal related pain. International Journal of Rehabilitation Research 30: 9-18.

Norrefalk JR, Littwold-Poljo A, Ryhle L, Jansen GB (2010). Effect on work ability after team assessment of functioning regarding pain, self-rated disability, and work ability assessment. Journal of Multidisciplinary Healthcare 3: 155-9.

Pollard CA (1984). Preliminary validity study of the pain disability index. Perceptual and Motor Skills 59: 974.

Scascighini L, Toma V, Dober-Spielmann S, Sprott H (2008). Multidisciplinary treatment for chronic pain: A systematic review of interventions and outcomes. Rheumatology 47: 670-8.

Soer R, Reneman MF, Patrick CAJ, Vroomen PCAJ, Stegeman P, Coppes M (2012). Responsiveness and minimal clinically important change of the Pain Disability Index in patients with chronic back pain. Spine 37: 711-5.

Sullivan MJL, Bishop SR, Pivik J (1995). The Pain Catastrophizing Scale: Development and validation. Psychological Assessment 7: 524-33.

Swedish Council on Health Technology Assessment (2010). Rehabilitation of patients with chronic pain conditions. A systematic review (2010) Available at http://www.sbu.se/ upload/publikationer/content1/1/smartrehab_eng_smf_ 110518.pdf [Accessed March 22, 2016].

van der Zee KI, Sanderman R (1993). Het meten van de algemene gezondheidstoestand met de RAND-36. Een handleiding [Measuring general health status with the RAND-36. A users manual]. Groningen: Northern Center of Health Care Research.

Waterschoot FP, Dijkstra PU, Hollak N, de Vries HJ, Geertzen JH, Reneman MF (2014). Dose or content? Effectiveness of pain rehabilitation programs for patients with chronic low back pain: A systematic review. Pain 155: 179-89.

Westman A, Linton SJ, Ohrvik J, Wahlen P, Theorell T, Leppert J (2010). Controlled 3-year follow-up of a multidisciplinary pain rehabilitation program in primary health care. Disability and Rehabilitation 32: 307-16.

Westman A, Linton SJ, Theorell T, Ohrvik J, Wahlen P, Leppert J (2006). Quality of life and maintenance of improvements after early multimodal rehabilitation: A 5-year follow-up. Disability and Rehabilitation 28: 437-46.

World Health Organization (2002). Handbook for good clinical research practice (GCP) Guidance for implementation. Available at http://www.apps.who. int/prequal/info_general/documents/GCP/gcpl.pdf [Accessed March 22, 2016]. 